\title{
A capa do livro e suas cores: o papel do matiz na interpretação da mensagem
}

\author{
The book's cover and its colors: the role of the hue in the message interpretation
}

\author{
Yasmine Lima, Carla Pereira
}

cor, capas de livros, semiótica, comunicação, design da informação

\begin{abstract}
Esta investigação tem como tema o Design Editorial, e como objeto de estudo capas de livros analisadas sob a perspectiva da cor. Considerando que para quase um terço dos leitores brasileiros o tema ou assunto é o principal fator para escolha de um livro, e que uma parcela importante destes afirma eleger um livro pela capa, destaca-se a importância que esta adquire na captação da atenção e na identificação do assunto tratado na obra. Sabe-se que as cores podem sugerir significados derivados de associações culturais e sociais, contudo, há pouco conhecimento sobre sua interferência na compreensão de mensagens visuais. Este artigo apresenta resultados iniciais de pesquisa de mestrado que investiga a influência dos matizes na interpretação da imagem gráfica no contexto de capas de livros. Mais especificamente, objetivou-se verificar se a cor da capa interfere na identificação do assunto tratado na obra pelos leitores. O estudo, de caráter exploratório, utilizou questionários estruturados, elaborados e aplicados com a ferramenta Typeform, distribuídos através de redes sociais. No experimento, a maioria dos participantes não identificou a categorização real das obras pela observação da capa. Pela grande dispersão observada nas respostas, foi verificado que o design das capas testadas gerou ambiguidade na identificação da temática dos livros. Aparentemente, a interpretação dos leitores foi conduzida principalmente pelas imagens contidas nas capas, já que eliminação dos matizes não alterou substancialmente os resultados. Por outro lado, as diferenças observadas nas respostas indicam ter ocorrido alguma influência de associações simbólicas das cores na interpretação do conteúdo.
\end{abstract}

color, book covers, semiotics, communication, information design

The thematic discussed by this research is the Editorial Design, and the book covers are the study subjects. The book covers were analysed from the color perspective. Taking in account that for almost one third of Brazilian readers the theme of the book is the main factor for its selection, and that a significant amount of the readers choose a book by its cover, it should be highlighted the importance of the the book cover for identifying the subject of the book. The colors may suggest meanings derived from cultural and social associations, however, there is limited understanding concerning its interference in understanding visual messages. This research presents the initial results of a master thesis which investigates the influence of the nuances in the interpretation of the graphic image in the context of book covers. More specifically, this study aimed to check if the color of the book cover interferes with the identification of the subject of the book by the readers. The study is exploratory in nature and used a structured questionnaire applied with a Typeform and distributed through the social networks. In this experiment, the vast majority of survey participants did not identify the categorization of works by observing the cover of the book. According to the dispersion observed in the answers, it has been checked that the design of the book covers generated ambiguity in the identification of the themes of the books. Apparently, the readers interpretation was carried out by the images on the covers since the elimination of the nuances did not substantially alter the results. On the other hand, the differences observed in the responses indicate symbolic association of colors in the interpretation of the content.

Anais do 9 $\mathrm{CIDI}$ e 9 CONGIC

Luciane Maria Fadel, Carla Spinillo, Anderson Horta,

Cristina Portugal (orgs.)

Sociedade Brasileira de Design da Informação - SBDI

Belo Horizonte | Brasil | 2019

ISBN 978-85-212-1728-2
Proceedings of the 9th CIDI and 9th CONGIC

Luciane Maria Fadel, Carla Spinillo, Anderson Horta,

Cristina Portugal (orgs.)

Sociedade Brasileira de Design da Informação - SBDI

Belo Horizonte | Brazil | 2019

ISBN 978-85-212-1728-2 


\section{Introdução}

Como fator de evolução e integração das sociedades, historicamente a comunicação se favoreceu de um artefato fundamental: o livro. Foi por meio da história oral e dos livros que a maioria dos povos repassou e perpetuou seu conhecimento. O primeiro livro impresso que se tem conhecimento no mundo foi a Bíblia de Gutemberg, de 1455. Segundo Machado (2017), no Brasil, a história do livro começa em 1747, quando um tipógrafo português imprime no Rio de Janeiro o primeiro folheto; porém, a coroa portuguesa proibiu a impressão na colônia, o que adiou a instalação da imprensa no país por mais de 60 anos.

Nos dias atuais, a produção e comercialização de livros são influenciadas por aspectos educacionais, sociais, econômicos, geográficos e políticos. Segundo dados do IBGE (2017), a taxa de analfabetismo da população a partir de 15 anos de idade no Brasil foi de 7\% em 2017. Em números absolutos, essa taxa representa 11,5 milhões de pessoas que não sabem ler e escrever no país. Há ainda o agravante de o número de analfabetos funcionais ser superior ao número de analfabetos absolutos, o que se reflete diretamente no mercado editorial brasileiro. Uma análise dos últimos doze anos realizada pela FIPE (2018) demonstra que o desempenho real do mercado livreiro no Brasil apresentou, de maneira geral, uma queda de faturamento ao longo dos anos, o que evidencia a necessidade de estudos e estímulos que favoreçam o setor.

A Norma Brasileira que trata da classificação dos livros quanto à tecnologia gráfica, o define como o conjunto de páginas reunidas no mesmo volume, sendo miolo o conjunto das páginas internas, e capa, a proteção que envolve o miolo (ABNT, 2012). Em geral, é por intermédio da capa que se tem o primeiro contato com um livro. Sua configuração é formada por diversos códigos, os quais produzem sentidos na mente do leitor, que interpreta o que vê e o que lê conforme sua própria visão de mundo. A cor utilizada em uma capa é um dos códigos que a compõem, e é sob a perspectiva do seu papel nesse processo de produção de sentidos que este estudo se desdobra.

Conforme Ambrose \& Harris (2009), no contexto de capas de livros, além da função estética, a cor pode fornecer informações, facilitar a transmissão de mensagens e ser utilizada como guia visual para o conteúdo da obra. Considerando que para $30 \%$ dos leitores brasileiros o tema ou assunto é o principal fator para escolha de um livro, e que $11 \%$ afirmam eleger um livro pela capa (Failla, 2016), destaca-se a importância que esta adquire na captação da atenção e na identificação do assunto tratado na obra.

A despeito da relevância dos diferentes elementos contidos no design e de suas interações na construção da mensagem visual, sabe-se que as cores podem sugerir significados derivados de associações culturais e sociais (Pastoureau, 1997; Heller, 2013). Contudo, há pouco conhecimento sobre sua interferência na compreensão de mensagens no contexto de capas de livros. Este artigo apresenta resultados iniciais de pesquisa de Mestrado que investiga a influência das cores na interpretação da imagem gráfica no contexto de capas de livros. Mais especificamente, objetiva-se verificar se a cor da capa interfere na identificação do assunto tratado na obra pelos leitores.

\section{Capas de livros e cores}

A área do conhecimento responsável pela produção de livros é o Design Editorial, que corresponde ao projeto visual de uma edição. Segundo Lopes (2013, p. 23):

Entende-se por edição o processo de planejamento envolvendo textos e imagens que irão compor uma publicação, sendo ela periódica ou não. Livros, jornais, revistas, e-books, são produtos de design editorial, onde mensagens visuais e textuais são ordenadas visando cumprir os objetivos de comunicação.

A palavra capa, derivada do latim, significa 'aquilo que serve para cobrir'; é a parte que envolve o miolo do livro, em geral confeccionada em papel de maior gramatura, que o protege e o identifica, por meio da linguagem verbal e não verbal. A capa do livro cumpre diferentes funções:

Anais do 9ํㅡㄹ Congresso Internacional de Design da Informação | CIDI 2019 
Surge como um mecanismo fundamentalmente prático, com o fim de proteger o miolo do livro, e que rapidamente ao longo da história acumula outros propósitos. A inclusão do título da obra e nome do autor permitiram que adquirisse também um papel informativo, ao passo que a decoração do espaço disponível passou a constituir uma forma de identificação e distinção do livro. (Carvalho, 2008, p.13).

Caldas (2009) explica que, ao se considerar o livro como um produto comercial, a capa passa a ser sua embalagem e ao mesmo tempo seu rótulo, o espaço publicitário que as editoras utilizam para atrair os leitores. Além de definir o livro como objeto, é uma das poucas embalagens que não é descartada, ela faz parte do livro e permanece unida ao mesmo durante seu uso.

Para a mesma autora, 'na construção de um discurso para uma capa de livro, a seleção dos signos, cores, imagens, textos, títulos e logomarcas, será responsável pelo sucesso ou fracasso na comunicação' (Caldas, 2009, p. 41). A autora acrescenta ainda que 'as capas são normalmente simbólicas e estabelecem uma relação com o imaginário do leitor que as apreende no seu todo, produzindo efeitos de sentido [...]' (Caldas, 2009, p. 41). Portanto, ao observar uma capa, o leitor irá interpretá-la envolvendo juízos de valor.

Nas capas, cores associadas a textos, imagens, formas, materiais e texturas, compõem uma mensagem a respeito do conteúdo da obra. Cores conotam significados e afetam a razão e emoção humanas. Sua percepção é influenciada por aspectos psicológicos, sociológicos e fisiológicos, e exerce papel fundamental no design como elemento de influência na decisão das pessoas. Para Arnkil (2013), as cores possuem grande potencial simbólico através de associações automáticas e criam símbolos fortes e memoráveis quando combinadas com a forma ou texto corretamente.

De acordo com Caivano (1998), os significados das cores adquirem seu caráter convencional/simbólico com o tempo e com seu uso repetido em diferentes contextos. Embora os significados atribuídos às cores possam mudar ao longo do tempo e entre diferentes culturas, existem associações que têm um caráter geral e recorrente (Tabela 1). Tais convenções devem ser consideradas e seu uso avaliado no contexto específico do projeto gráfico, de acordo com a mensagem que se pretende transmitir.

Tabela 1: Alguns significados atribuídos às cores por convenção. (Fonte: elaborado pelas autoras, baseado em Heller (2014); Pastoureau (1997).)

\begin{tabular}{l|l} 
Cores & Significados \\
\hline vermelho & Perigo, proibição, amor \\
\hline verde & Esperança, permissão, ecologia \\
\hline azul & Frio, nobreza, infinito \\
\hline amarelo & Calor, riqueza, alegria \\
\hline preto & Luto, morte, elegância \\
\hline branco & Paz, pureza, limpeza \\
\hline
\end{tabular}

Conforme observado na Tabela 1, as associações para uma mesma cor podem ser muito distintas, sugerindo respostas emocionais positivas e negativas para uma mesma cor. Isto corrobora o fato de que a cor por si só não apresenta um significado específico se não estiver associada a um contexto que lhe promova um sentido. Kuehni (2005, p. 37, tradução nossa) afirma que 'as experiências de cores que temos são o resultado da situação total em que elas são obtidas', dessa forma não devem ser consideradas isoladamente. Solli \& Lenz (2011) explicam que o conteúdo da imagem em geral, e não apenas o conteúdo colorido, afetará a resposta emocional do usuário. Para os autores, algumas imagens podem ter conteúdo emocional intimamente relacionado a emoções evocadas pela cor; porém, em outras, o conteúdo simbólico da cor ficará subjugado ao conteúdo da imagem.

Segundo Pereira (2012) é importante utilizar a cor adequada para se atingir determinados propósitos da comunicação, já que seu uso pode transmitir uma ideia diferente da almejada. Estudos como o de Zhang, Bao \& Xiao (2018, p. 2) confirmaram a hipótese de que a congruência entre texto e cor - quando o conteúdo do texto e do significado transmitido pela cor são correspondentes - facilita a eficácia da mensagem.

No design de capas de livros, as cores podem antecipar informações vinculadas à obra, mas também podem causar ambiguidade e dificultar a interpretação para o leitor. É a partir

Anais do 9ำ Congresso Internacional de Design da Informação | CIDI 2019 Proceedings of the 9th Information Design International Conference 
desse pressuposto que se pretende investigar a relação entre as cores das capas de livros e o assunto abordado na obra, verificando como essa associação é percebida e interpretada pelo público leitor.

\section{Método}

Esta investigação situa-se na área de Design da Informação, tendo como tema o Design Editorial e como objeto capas de livros analisadas sob a perspectiva da cor. Em relação à sua natureza, trata-se de pesquisa aplicada, fundamentada pela linha teórica pragmática. Quanto aos objetivos, caracteriza-se como pesquisa exploratória, envolvendo procedimentos de pesquisa bibliográfica e pesquisa experimental. No que se refere à natureza dos dados será utilizada a pesquisa qualitativa, com análises do experimento gerando dados quantitativos.

O estudo exploratório aqui relatado utilizou questionários estruturados, elaborados e aplicados com a ferramenta Typeform, distribuídos através de redes sociais. Foram utilizadas fotografias de duas capas de livros de literatura adulta, com predominância de uma cor, e cujo assunto tratado na obra não estava evidenciado nas imagens contidas no design. Foram observados os seguintes critérios de seleção: (1) uma capa cuja cor apresentasse associação simbólica (convencional) com o assunto da obra (Capa 1); e (2) uma capa na qual essa relação não fosse convencional (Capa 2) (Figura 1).

Figura 1: Design original das capas utilizadas no experimento (Fonte: Elaborado pelas autoras, a partir da capa dos livros Maestra e A Esperança).

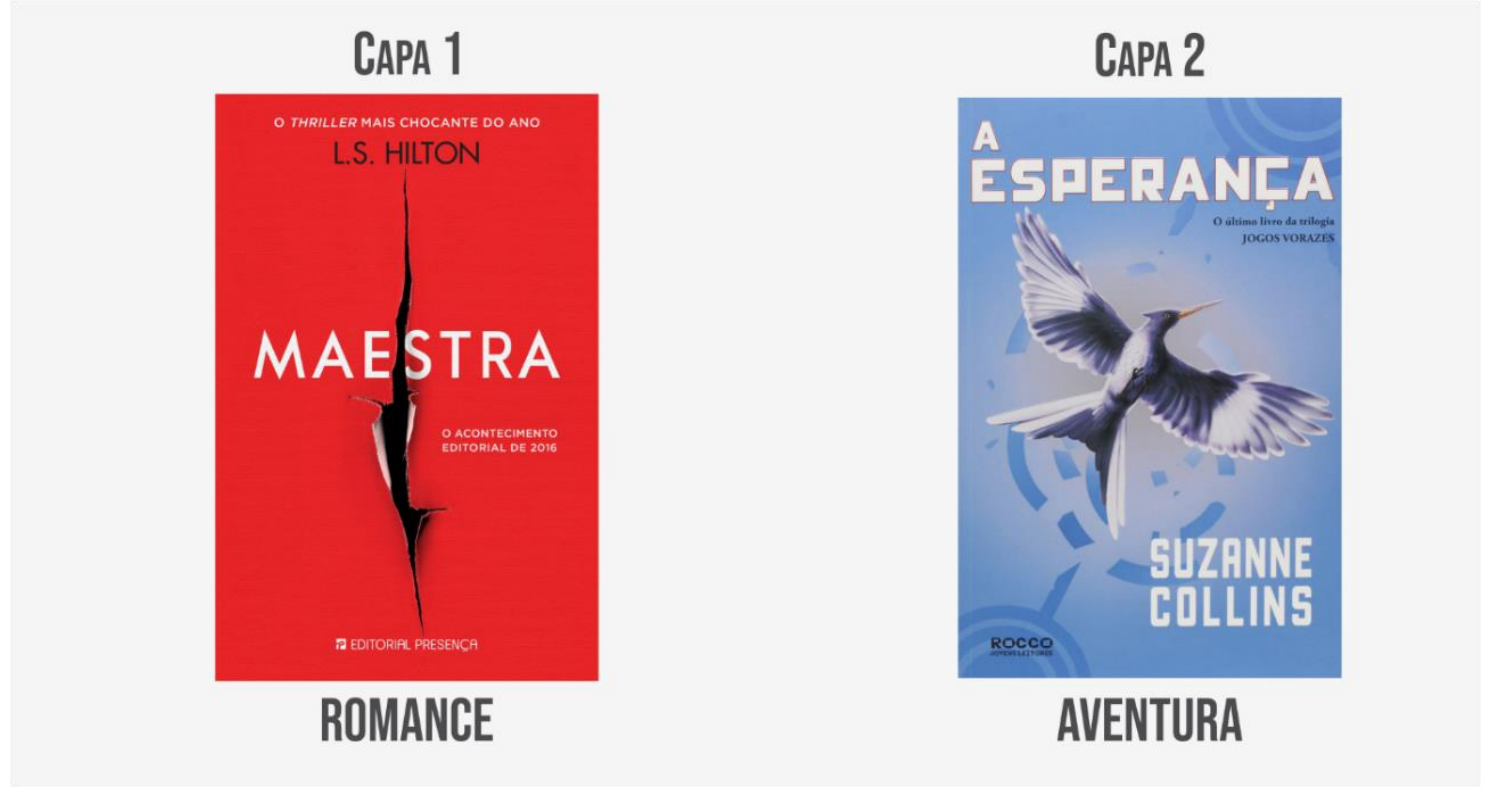

Os questionários foram respondidos por 68 indivíduos adultos alfabetizados, de ambos os sexos. As duas capas foram expostas a dois grupos distintos de 34 pessoas cada, retirando-se o título e textos que remetessem ao assunto. Para o Grupo A, o design foi mantido na cor original, e para o Grupo B, as cores foram convertidas para tons de cinza, utilizando-se o software Photoshop CC, sendo suprimidos os matizes e preservadas as relações de claridade das cores originais (Figuras 2 e 3 ).

Cada participante só entrou em contato com uma das versões da capa (colorida ou em tons de cinza), uma vez que a percepção de uma poderia influenciar a outra. Esta estratégia de pesquisa experimental é denominada design-between-subjects. Dessa forma, ao apresentar as peças gráficas nas cores originais para um grupo de sujeitos e em tons de cinza para outro grupo, dando-lhes as mesmas opções de respostas, foi possível compará-las, levando em conta que a única variável entre elas foi a cor. As respostas obtidas forneceram subsídios para 
as análises, que buscaram compreender qual influência da cor para a identificação do assunto tratado no livro.

Todos os participantes responderam à seguinte questão: 'Observando a capa você acha que este é um livro de:'. Todos os questionários continham as seguintes alternativas de resposta: autoajuda, ação/aventura, biografia, científico, conto/crônica, culinária, didático, ficção científica, horror/terror, humor, infantil, poesia, política, romance e religião/esoterismo; além de uma alternativa aberta para digitar outra resposta que não estivesse entre as apresentadas. Estas opções foram escolhidas de acordo com as categorizações mais recorrentes observadas em livrarias online. Os livros testados estão inseridos nas categorias romance e ação/aventura, respectivamente.

Em relação à amostragem, por ser uma pesquisa qualitativa cuja população não pôde ser determinada, foi utilizada a amostragem não probabilística por conveniência. O Teorema do Limite Central estabelece 'que amostras maiores do que 30 são normais, independentemente do formato da distribuição de probabilidade da população da qual está sendo retirada a amostra' (Luchesa, 2011, p. 43). No caso desta pesquisa este número dobrou, pois foram dois questionários aplicados para dois grupos diferentes. O objetivo deste experimento foi investigar se os matizes utilizados nas capas influenciam os leitores na comunicação do assunto tratado no livro.

\section{Resultados e discussão}

Foram respondidos no total 68 questionários, 34 para cada grupo de pessoas; porém, os respondentes que afirmaram conhecer algum dos livros foram eliminados da análise, restando 30 questionários para cada grupo.

Quanto ao perfil dos respondentes, para o questionário o 1 (imagens em tons de cinza), dos 30 participantes considerados, 17 foram mulheres $(57 \%)$ e 13 homens $(43 \%)$, com idades variando entre 21 e 43 anos, a maioria com grau de escolaridade em nível de pós-graduação. Para o questionário no 2 (imagens coloridas), dos 30 indivíduos, 23 foram mulheres (77\%) e 7 homens (23\%), com idades variando entre 23 e 61 anos, a maioria também com pósgraduação.

O livro Maestra (Figura 1) é considerado um romance e foi escolhido por ter na capa a predominância da cor vermelha, que apresenta associação simbólica com a ideia de amor e paixão (Heller, 2014; Pastoureau, 1997), concordando assim com ideia geral da classificação da obra. Na Figura 2 são apresentados os resultados obtidos para essa capa sem a informação do título da obra, apresentada em tons de cinza para um grupo e nas cores originais e para outro.

Figura 2: Livro Maestra: comparação entre as respostas para capa na cor original e em tons de cinza, ambas sem o título da obra (Fonte: Elaborado pelas autoras)
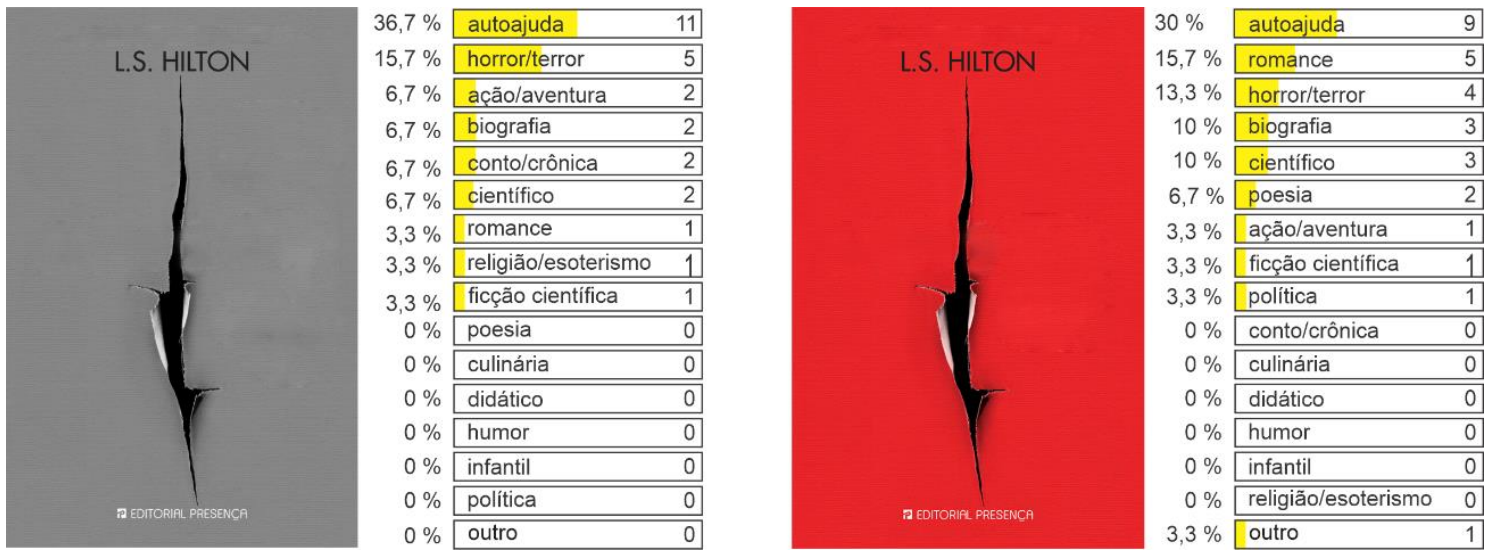

Anais do 9 Congresso Internacional de Design da Informação | CIDI 2019

Proceedings of the 9th Information Design International Conference

Anais do $9^{\circ}$ Congresso Nacional de Iniciação Científica em Design da Informação | CONGIC 2019

Proceedings of the $9^{\text {th }}$ Information Design Student Conference 
Constata-se que, nos dois grupos, houve grande dispersão nas respostas e cerca de um terço dos participantes classificou o livro como autoajuda, independente da cor da capa. Porém, o número de pessoas que considerou o livro como romance foi maior para capa vermelha $(15,7 \%)$ do que para a capa cinza $(3,3 \%)$.

O livro A Esperança (Figura 1), classificado como ação/aventura, foi escolhido por sua capa ter a predominância da cor azul clara, que não possui associação simbólica com esse conceito, de acordo com a bibliografia consultada (Heller, 2014; Pastoureau, 1997). Na Figura 3, podem ser observados os resultados obtidos para essa capa sem a informação do título da obra, apresentada em tons de cinza para um grupo de pessoas e nas cores originais e para outro.

Mais uma vez, nos dois grupos, houve grande dispersão nas respostas e cerca de um terço dos participantes classificou o livro como autoajuda, independente da cor da capa. Por outro lado, o número de pessoas que identificou o livro como religião/esoterismo foi maior para a capa azul $(26,7 \%)$ do que para a capa sem esse matiz (16,7\%) (Figura 3).

Figura 3: Livro A Esperança: comparação entre as respostas para capa na cor original e em tons de cinza, ambas sem o título da obra (Fonte: Elaborado pelas autoras)
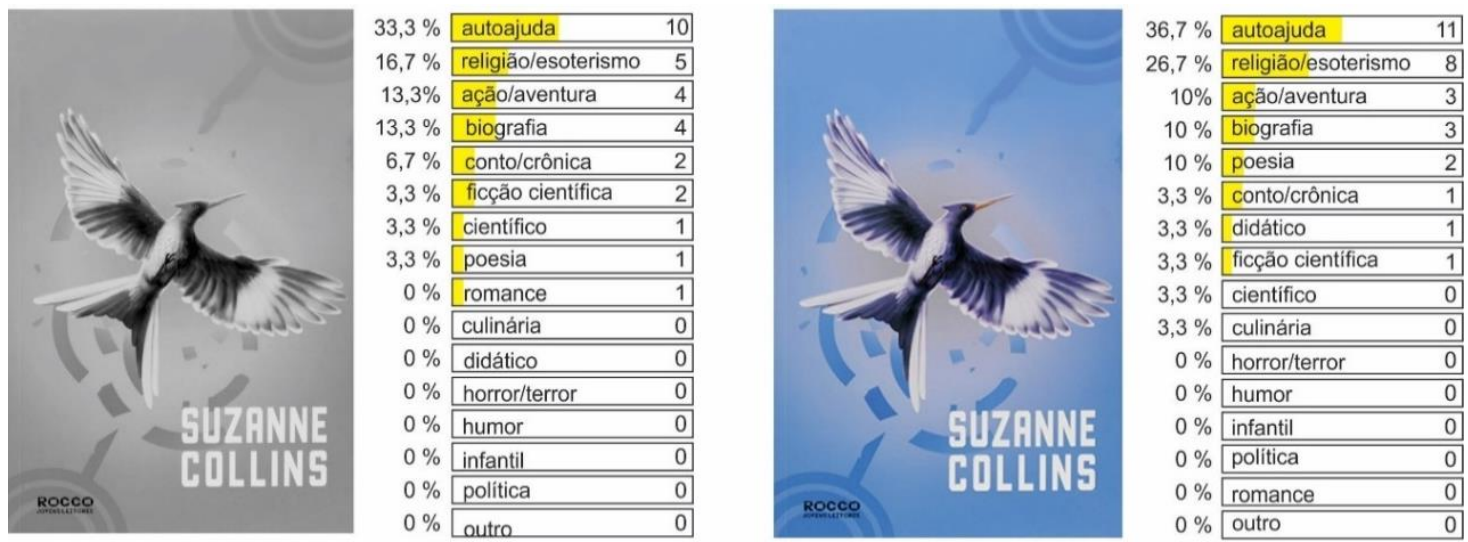

No experimento, a maioria dos participantes não identificou a categorização real das obras pela observação da capa sem a informação do título da obra. Cerca de um terço deles considerou serem ambos livros de autoajuda, independente da imagem ter sido apresentada em cores ou em tons de cinza. Contudo, para a Capa 1 (livro Maestra), cujo vermelho da capa possui associação simbólica com a categoria romance na qual o livro é classificado, o número de pessoas que o identificou como tal foi maior para a capa vermelha do que para a versão sem o matiz. Outra classificação recorrente observada para as duas versões desta capa foi horror/terror, com resultados próximos para o vermelho e para o cinza.

No caso da Capa 2 (livro A Esperança), cuja cor azul clara não tem relação simbólica com a classificação do livro (ação/aventura), o número de acertos foi pequeno e semelhante para as duas versões da capa, sendo ligeiramente maior para a versão em tons de cinza. Para o mesmo livro, além de autoajuda (a classificação mais frequente), outra classificação recorrente foi religião/esoterismo, neste caso com frequência maior para a capa azul clara do que para a capa cinza.

\section{Considerações finais}

Pela grande dispersão observada nas respostas, foi verificado que o design das capas testadas gerou ambiguidade na identificação da temática dos livros. Aparentemente, a interpretação dos leitores foi conduzida principalmente pelas imagens contidas nas capas, já que eliminação dos matizes não alterou substancialmente os resultados. É importante destacar que a conversão das cores em tons de cinza preservou as relações de claridade das imagens, o que pode ter contribuído para as semelhanças das respostas entre as duas versões de cor testadas. Por outro lado, as diferenças observadas nas respostas indicam ter ocorrido alguma influência de associações simbólicas das cores na interpretação do conteúdo, particularmente na relação entre vermelho e romance, e entre azul claro e religião/esoterismo.

Anais do 9ํㅡㄹ Congresso Internacional de Design da Informação | CIDI 2019

Proceedings of the 9th Information Design International Conference

Anais do $9^{\circ}$ Congresso Nacional de Iniciação Científica em Design da Informação | CONGIC 2019

Proceedings of the $9^{\text {th }}$ Information Design Student Conference 
O experimento permitiu avaliar o método de pesquisa bem como a técnica de coleta de dados, que demonstraram ser adequados aos objetivos da investigação, embora necessitando ajustes. Por se tratar de etapa inicial de pesquisa, os resultados ainda serão submetidos a análises mais aprofundadas, com base em referencial teórico específico, visando à formulação de hipóteses a serem investigadas em etapas posteriores. Por fim, para a continuidade desta pesquisa, recomenda-se a ampliação da amostra, bem como a inclusão de questões complementares que forneçam indicações mais precisas sobre os elementos do design que influenciam a interpretação dos leitores.

\section{Referências}

ABNT. (2012) NBR 14869-1: Tecnologia gráfica - Livros Parte 1: Classificação. Rio de Janeiro.

Ambrose, G. \& Harris, P. (2009). Design básico cor. Tradução Francisco Araújo da Costa. Porto Alegre: Bookman.

Arnkil, H. (2013). Colours in the visual world. Helsinki: Aalto University.

Caivano, J. (1998). Color and Semiotics: a two-way street. Color Research and Application, United States, n. 6, vol XXIII, p. 389-401.

Caldas, S. (2009). Gabriela baiana de todas as cores: as imagens das capas e suas influências culturais. Salvador: EDUFBA.

Carvalho, A. (2008). A capa de livro: o objecto, o contexto, o processo. 98 f. Dissertação (Mestrado). Porto: Universidade do Porto.

Failla, Z. (2016). Retratos da leitura no Brasil 4. Rio de Janeiro: Sextante.

Heller, E. (2013). A psicologia das cores: como as cores afetam a emoção e a razão. 1. ed. São Paulo: G. Gili.

Kuehni, R. (2005). Color: an introduction to practice and principles. Second Edition. John Wiley \& Sons.

Lopes, W. (2013). Design editorial. Em R. Nicolau (Org.). Zoom: design, teoria e prática. 1ed., p. 20-29. João Pessoa: Ideia.

Luchesa, C. \& Chaves Neto, A. (2011). Cálculos do tamanho da amostra nas pesquisas em administração. 21 ed. Curitiba: Edição do autor. 43 p.

Machado, U. (2017). A capa do livro brasileiro 1820-1950. São Paulo: Ateliê Editorial, SESI-SP Editora.

Pastoureau, M. (1997). Dicionário das cores do nosso tempo: simbólica e sociedade. Tradução Maria José Figueiredo. Lisboa: Editorial Estampa.

Pereira, C. (2012). A cor como espelho da sociedade e da cultura: um estudo do sistema cromático do design de embalagens de alimentos. 376 f. Tese (Doutorado). São Paulo: Universidade de São Paulo.

Solli, M. \&, Lenz, R. (2011). Color emotions for multi-colored images. Color Research and Application, v. 36, n. 3, p. 210-221, jun.

Zhang, T.; Bao, C. \& Xiao, C. (2018). Promoting effects of color-text congruence in banner advertising. Color Research and Application, p. 1-7.

\section{Sobre as autoras}

Yasmine Lima; mestranda, UFCG, Brasil <yasmine_lima@hotmail.com>

Carla Pereira; Doutora, UFCG, Brasil <carlapereira.ufcg@gmail.com>

Anais do 9 Congresso Internacional de Design da Informação | CIDI 2019 